\title{
VI CONGRESO NACIONAL DE ALIANZA POPULAR
}

Del 27 al 29 del pasado mes de enero se celebró en Barcelona el VI Congreso Nacional de Alianza Popular, que presentaba, entre otras notas de interés, la de conocer las líneas ideológicas que informarán la actuación del primer partido en la oposición durante los próximos meses y los principios básicos en que, presumiblemente, basarán su campaña electoral en las próximas elecciones generales españ̉olas.

No se puede discutir la ascensión de Alianza Popular como partido político desde 1977 hasta este VI Congreso Nacional. Durante estos seis años de actuación: política, Alianza Popular ha pasado de una reducidísima representación en las. Cortes, en los inicios de la transición política, contar con un importante número. de representantes en las Cámaras españolas, que respaldan la afirmación acerça de su innegable progreso.

A pesar de todo, tal progreso, sin duda atribuible en parte a la mejor organización e imagen del partido, ha estado también influido decisivamente por la desaparición de un centro que, actuando coherentemente, bien hubiera podido aglụtinaren torno a sí un buen número de votos no socialistas, pero tampoco identificados. con el conservadurismo defendido por Alianza Popular. De esta realidad derivan las. continuas referencias de este partido político respecto de la necesidad de implantar en España un bipartidismo político.

En cuanto al contenido de este VI Congreso Nacional, podemos señalar, como. aspectos más importantes, los siguientes:

\section{A) La organización del partido}

En la ponencia de «Organización y Estatutos» presentada a este VI Congreso Nacional se destacó la necesidad de adecuar las normas de organización del partido a la experiencia de la práctica política y a las nuevas circunstancias de la democracia española. La tendencia acogida es a una mayor objetivación, a una institucionalización e integración del partido como un elemento de la estructura político-social del país.

El artículo 2: $:^{\circ}$ de los Estatutos del partido contiene la definición ideológica, configurándose Alianza Popular «como un partido democrático, liberal-conservador, reformista e interclasista», que, inspirándose en los principios del humanismo cristiano, tiene como fin aglutinar al sector moderado de la opinión pública de nuestro país para lograr una «España justa, libre, pacífica, próspera y unida». 
Los Estatutos del partido resultan especialmente estrictos en lo que se refiere a la disciplina interna de los afiliados, prohibiéndose expresamente las manifestaciones contrarias al programa del partido o a la actuación de sus dirigentes, así como las actividades encaminadas a crear corrientes de opinión organizadas en el seno del partido.

En cuanto a la organización, a nivel nacional, el partido se estructura a través de los siguientes órganos:

\section{De competencia general}

El Congreso Nacional

La Junta Directiva Nacional

El Comité Ejecutivo Nacional

El presidente

La Secretaría General

La oficina central

\section{De Competencia objetiva especial}

El Consejo Político Nacional

El Comité Electoral Nacional

El Comité Nacional de Conflictos y Disciplina

La Comisión Nacional de Autonomías

Las Comisiones de Estudio

\section{B) Política y economia}

Como ya hemos dicho anteriormente, en este VI Congreso Nacional, Alianza Popular se ha definido como un partido «liberal-conservador», expresión que ha sido utilizada profusamente durante este Congreso para delimitar la actuación política y económica del partido para el futuro.

Sin duda, uno de los fines principales de este VI Congreso era, como ya también antes hemos mencionado, adecuar la imagen del partido a las circunstancias de la política nacional en la actualidad; había un claro deseo de matizar algunos aspectos ideológicos, suavizando formas, de manera que se posibilite para el futuro una posible unión o colaboración política con partidos menos conservadores de lo que, hasta ahora, se desprendía del programa y de la imagen de Alianza Popular.

Se ha insistido, por parte de Alianza Popular, como dijimos al principio, en la conveniencia de estructurar las fuerzas políticas españolas en torno a dos únicas opciones: de configurar, en suma, un bipartidismo, en el que uno de los polos estaría representado, indudablemente, por la Coalición Popular, en la que está integrada Alianza Popular, mientras que el otro polo lo constituirian las fuerzas de «izquierdas».

En cuanto a las directrices económicas, son expresión clara de un liberalismo muy acentuado, con un desarrollo progresivo del sector privado y la consecuente contracción del sector público. Como es sabido, la enunciación, en términos económicos, de programas liberales es no sólo posible, sino, en ocasiones, una construcción teórica muy coherente, pero los problemas de los programas liberales derivan no de su enunciación teórica, sino de su aplicación práctica, y todo ello a pesar de las grandes contradicciones que afectan actualmente al Estado interventor mayoritariamente extendido en los países occidentales.

\section{C) Política exterior}

En cuanto a las directrices a seguir en defensa internacional, Alianza Popular considera que la OTAN es la representación de unos ideales de ayuda mutua y una necesidad para la seguridad de la civilización occidental, descartando cualquier posibilidad de que España se constituyera como país neutral.

Igualmente se muestran partidarios de otorgar una atención preferente a las relaciones con Estados Unidos, tanto a nivel militar como comercial. La integración 
en la Comunidad Económica Europea se considera positiva, aunque sería, en todo caso, necesario atender al «cómo» y al «precio» de tal integración.

Por último, respecto a este apartado reseñaremos que Alianza Popular considera necesaria la reivindicación continuada de Gibraltar como territorio español ante las autoridades británicas.

\section{D) Sociedad}

Coherentemente con otros postulados de su programa político, Alianza Popular considera que la política social debe apoyarse en el sector privado más que en el público; en la libertad económica más que en el proteccionismo.

En cuanto al sistema de Seguridad Social, debería, según las conclusiones de este VI Congreso, articularse en torno a un sistema básico de carácter público y, en función del artículo 41 de la Constitución española de 1978, otro complementario de carácter privado.

Quizá, dentro de este apartado, sea de interés señalar los postulados básiços en torno a dos aspectos concretos: educación y familia.

a) En cuanto al sistema educativo, se declaran partidarios de la gratuidad de la enseñanza hasta los dieciséis años, con posibilidad de elección del centro, lo que básicamente se traduce en la necesidad de amplias subvenciones al sector privado de la educación.

b) En lo referente a la familia, como corresponde a un partido de ideología conservadora, Alianza Popular lleva a cabo en su programa una encendida defensa de la institución familiar basándola, además, en el matrimonio que se constituye «como comunidad de vida y amor y teniendo como fin la procreación, la educación y el desarrollo personal de sus miembros y el progreso de la sociedad") (Ponencia de Educación y Familia).

En la ponencia mencionada se llega a hablar, incluso, de «familias incompletas», terminología más que discutible, para definir el supuesto de la maternidad no matrimonial. Otro de los aspectos más destacables es la defensa de la profesionalización del ama de casa, refiriéndose al trabajo de las mujeres fuera del hogar propio sobre todo en «casos de necesidad». Preconizan, consecuentemente con todo lo dicho, un sistema fiscal que no penalice la institución familiar.

\section{E) Los dirigentes del partido}

$\mathrm{Ha}$ permanecido, en este VI Congreso Nacional, indiscutido el liderazgo de Manuel Fraga y, básicamente, también el de su «equipo» habitual, con la excepción de Fernando Suárez, que ha dejado la Vicepresidencia que ocupó hasta este Congreso, con manifiestas críticas a la falta de democracia interna del partido, especialmente por la presentación de una única lista para la elección de la ejecutiva del partido en este Congreso.

Permanecen, por tanto, Manuel Fraga como presidente de Alianza Popular y Jorge Verstrynge como secretario general, y junto a ellos, entre otros, Alfonso Ossorio, Gerardo Fernández-Albor, Abel Matutes y Miguel Herrero Rodríguez de Miñón, que consiguió una aclamación prácticamente unánime por la defensa que realizó de la ponencia política presentada a este Congreso. 


\section{F) El desarrollo del Congreso}

En cuanto al desarrollo de este VI Congreso Nacional de Alianza Popular, podríamos decir que ha estado presidido por una carencia casi absoluta de crítica interna y por un cierto espíritu de triunfalismo, originándose los debates más controvertidos en la discusión de la ponencia de Estatutos.

Por otro lado, este Congreso ha resultado una aclamación constante para su líder más significativo, Manuel Fraga, que parece así mantener su hegemonía dentro del partido.

En general, el funcionamiento interno de este Congreso ha sido de asentimiento generalizado y ha mostrado, sin duda, la incondicionalidad de sus integrantes respecto a los principios que defiende Alianza Popular.

YoLANDA GÓMEZ SÁNCHEZ

Fuente: Ponencias e información aportados por Alianza Popular en Madrid. 